Portland State University

PDXScholar

$1-1-2013$

\title{
Following the Teacher's Lead in Professional Development to Improve Classroom Talk Around Texts
}

Dot McElhone

Portland State University

Teri Tilley

Follow this and additional works at: https://pdxscholar.library.pdx.edu/edu_fac Let us know how access to this document benefits you.

\section{Citation Details}

McElhone, Dot and Tilley, Teri, "Following the Teacher's Lead in Professional Development to Improve Classroom Talk Around Texts" (2013). Education Faculty Publications and Presentations. 9.

https://pdxscholar.library.pdx.edu/edu_fac/9

This Post-Print is brought to you for free and open access. It has been accepted for inclusion in Education Faculty Publications and Presentations by an authorized administrator of PDXScholar. Please contact us if we can make this document more accessible: pdxscholar@pdx.edu. 


\begin{abstract}
This study examines the process of teacher learning in the context of highly responsive, ongoing professional development centered on classroom talk around texts. A classroom teacher and a university researcher met weekly to view, analyze, and discuss videos of reading instruction recorded in the teacher's fifthgrade classroom. The professional development sessions were framed as teacherdriven action research. This paper traces the evolution of the intensive professional development activity across one semester and describes the process by which the teacher-researcher appropriated practical and conceptual tools for facilitating class discussions of texts. Results highlight the value of positioning teachers as intellectually capable and honoring their agendas for professional development. Insights are offered regarding a model of professional development that can support teacher agency, address local problems of practice, and simultaneously leverage professional developer expertise to build both new practices and new concepts that can be used to solve novel problems.
\end{abstract}

Keywords: teacher professional development, inservice teacher education, class discussion, discourse analysis, action research, activity theory 
Following the Teacher's Lead in Professional Development to Improve Classroom Talk Around Texts

Although talk is an essential medium for learning (Wertsch, 1998), most teachers do not receive professional development focused explicitly on classroom talk. Further, much inservice professional development fails to respond to teachers’ needs because it either occurs as a one-shot experience (Garet, Porter, Desimone, Birman, \& Yoon, 2001) or focuses on implementation of prescribed curricula rather than addressing issues that concern teachers (Wilson \& Berne, 1999). This study examines the process of teacher learning in the context of highly responsive, ongoing professional development centered on classroom talk around texts and reading comprehension strategies.

Classroom talk has implications for student learning and achievement. For example, eighth-grade students who reported more frequent discussions of texts in their English classes scored higher on the 2011 NAEP Reading test than did their counterparts who reported less frequent discussions (NCES, 2011, p.48). Similarly, Gamoran and Nystrand (1991) found that the amount of classroom discussion in English and social studies classes was a strong predictor of reading achievement. Researchers have also identified the positive effects on reading achievement of a range of discourse-focused instructional approaches, such as Reciprocal Teaching (Palincsar \& Brown, 1984) and Questioning the Author 
(McKeown, Beck, \& Blake, 2009). To be as effective as possible, teachers need tools to help them facilitate engaging classroom talk.

The individualized professional development (PD) sessions described in this paper involved in-depth analysis of talk in the teacher-researcher's (TR's) classroom. The professional development experience was framed as teacherdriven action research (Pine, 2008) in an effort to disrupt the "perceived hierarchical relationship” (Wells, 2011, p. 168) between researcher and teacher. The inquiry evolved through an iterative process in which the university researcher (UR) aimed to support the TR's inquiry into her classroom discourse practices.

This ongoing, collaborative approach to PD rooted in problems of practice identified by the TR aligns with a consensus among scholars who call for “providing collegial opportunities to learn that are linked to solving authentic problems” (Hawley \& Valli, 1999, p. 127). Despite this consensus, many PD opportunities "remain as episodic updates of information delivered in a didactic manner” (Webster-Wright, 2009, p.703). One goal of our study was to explore a PD approach that respects teachers as capable and committed to learning and developing their practice.

\section{Theoretical Framework}

\section{Activity Theory}

Activity theory (Cole, 1996; Engeström, 1987) served as our framework for 
the design of the PD experience and the data analysis. "Broadly defined, activity theory is a philosophical and cross-disciplinary framework for studying forms of human practices as development processes, with both individual and social levels interlinked” (Kuutti, 1996, p.25). From this perspective, development occurs through reflective engagement in contextualized activity mediated by tools and by social relationships.

The PD sessions constitute the key activity setting explored in this study (Cole, 1996). Within an activity setting, activity is defined as "a form of doing directed to an object” (Kuutti, 1996, p. 27). The object of our PD activity was the TR's instructional practice of classroom discourse during reading instruction. In proposing the project, the UR's motive was to help the TR transform her current practice in a way that would develop her "adaptive expertise” (Hatano \& Inagaki, 1986) for classroom discourse. This would mean strengthening the TR's ability to implement routines efficiently and her ability to solve novel problems innovatively in the domain of classroom talk. Such expertise is essential to effective teaching (Bransford, Derry, Berliner, Hammerness, \& Beckett, 2005) and requires that teacher education support both conceptual understanding and practical knowledge.

Mediation among the components of an activity is central to activity theory. The subject of the activity acts on the object (e.g., teaching practice) not directly, but through the use of tools. The relationship between the community members in 
an activity setting and the object is mediated by the division of labor (i.e., the roles played by each individual). The relationship between the focal subject and the community is mediated by explicit and implicit rules and norms for behavior. These multiple components and relationships are intertwined such that when a change occurs in one part of the activity system (e.g., the division of labor among community members), changes are likely (though not inevitable) in other parts of the system.

\section{Conceptual and Practical Tools}

While our analysis addresses all components of the PD activity, we focus particular attention on the tools mediating the relationship between the TR and her instructional practice around classroom discourse (the object). Adapting the framework used by Grossman, Valencia, and Smagorinsky (1999) to our focus on analyzing classroom talk as a method of inquiry into teaching practices, the PD process incorporated three categories of tools. Practical teaching tools are “classroom practices, strategies, and resources that ... [have] local and immediate utility” (p. 14), such as journal writing, textbooks, and other curriculum materials. Similarly, practical research tools are practices, strategies, and resources used for conducting research, such as transcripts, coding procedures, and data displays.

In their classification of pedagogical tools, Grossman and her colleagues define conceptual tools as "principles, frameworks, or ideas ... that teachers use 
as heuristics to guide decisions about teaching and learning” (p. 14). These tools, which include theoretical principles and concepts, help teachers think about and make decisions about their instructional practices. In our study, positioning the teacher as a co-researcher meant she would need a set of conceptual tools relevant both to teaching and to discourse analysis (i.e., our intended mode of inquiry into discourse processes in her classroom). Conceptual discourse analysis tools refer to constructs and frameworks for thinking about classroom talk that are relevant both to the teacher's classroom role and to her researcher role. An example is the Vygotskian (1986) notion that talk is not simply a medium through which we demonstrate understandings, but a tool with which we clarify, manipulate, and develop our understandings. Discourse analysts also use the implicit location of knowledge conveyed through talk as a tool for understanding power relationships in social settings (Bloome, Carter, Christian, Otto, \& Shuart-Farris, 2005). In the context of talk about texts, the location of knowledge has implications for the kinds of interpretations that are viewed as valid and the kinds of evidence that can legitimately support a claim. These issues are rooted in power relationships and intertwined with the ways participants in discourse position themselves and one another (Harré \& van Langenhove, 1998). A teacher developing adaptive expertise around her classroom discourse practices would need to be cognizant of the ways in which (a) discourse can contribute to the construction of student identity, (b) patterns of talk can locate authoritative knowledge and power with 
the teacher, and (c) talk moves (participants’ contributions during interactions) can implicitly position both students and teacher.

\section{Appropriation}

The PD activity was designed to develop the TR's adaptive expertise regarding classroom talk through her appropriation of conceptual discourse analysis tools, practical research tools, and practical teaching tools relevant to our inquiry. "Appropriation refers to the processes through which a person adopts the pedagogical tools available for use in particular social environments ... . [and] internalizes ways of thinking endemic to specific cultural practices” (Grossman et al., 1999, p. 15). In envisioning the study, the UR imagined that as the TR began to raise questions about her own practice, the UR would offer conceptual discourse analysis tools and practical research tools to help the TR delve into the nuances of discourse in her classroom. The TR would use some of the concepts about discourse to help her frame an action research inquiry. In the process of collecting and analyzing data about talk in her classroom, the TR would begin to generate new practical teaching tools to make her classroom discourse practices more effective. We discussed this PD structure before embarking on the project; the TR was motivated to inquire into discourse processes in her classroom and hopeful that the process would help to improve her teaching practices.

\section{Focus of the Study}


This research project examined the dynamics of our PD activity setting and pursued the following questions:

1. How did the PD activity evolve over the course of the project?

2. What practical and conceptual tools were appropriated by the TR?

3. How did the process of appropriation unfold?

4. How was the process of appropriation shaped by other components of the activity setting?

\section{Method}

\section{Context and Participants}

This multi-level study centered on one diverse fifth-grade classroom at Glenwood Elementary (pseudonym), a Title I school in the Pacific Northwest. In the years prior to data collection, Glenwood had been a small school of approximately 200 students in grades K-6 located in an aging building. Just before the study began, Glenwood started a school year in a newly constructed building with an student population (over 400 students).

The TR (second author), who is European American, was one of two fifthgrade teachers at the school and had experience in both primary and middle grades. She is also a doctoral student at the first author's institution (though not the first author's advisee or a student in her department), and earned an elective credit for her participation in the project. The TR's class included 32 students, of whom 17 were female and 15 were male. Six students identified as Latino/a, 1 as 
African American, 1 as mixed race, and the remainder as European American. According to assessments (e.g., Dynamic Indicators of Basic Early Literacy Skills [DIBELS] and Developmental Reading Assessment [DRA]), students’ reading levels ranged from first grade to well above grade level.

The TR used the "Daily Five” approach (Boushey \& Moser, 2006) to structure her reading block. This meant that students alternated between wholeclass lessons on the carpet and more independent work, such as independent reading, partner reading, and word work. Whole class lessons addressed comprehension strategies and usually incorporated class discussion. During independent work time, the TR worked with small, leveled guided reading groups to reinforce the strategies taught to the whole group and provide individualized support as students read novels and leveled readers. Students in these groups discussed inferences and interpretations of texts.

Any activity setting is influenced by the histories, experiences, and memberships in other activity settings of the participants. Each participant's actions, goals, and perceptions about appropriate roles are shaped by the norms of their larger communities. For instance, the TR's participation in the PD activity was informed by her role as a classroom teacher in a school struggling to meet the Adequate Yearly Progress goals of No Child Left Behind (NCLB, 2002) and by her employment in a district facing severe budget cuts. Although the TR had eight years of teaching experience at the time of the study, several of those 
occurred in another state, placing her near the bottom of the seniority ranking in her district and at risk of being laid off. The pressure to produce adequate scores on the statewide standardized test also factored into the TR's experience of and actions in the PD activity setting.

As a former middle grades classroom teacher and a researcher aware of the importance of relevance and teacher voice in PD, the UR (first author) aimed to position the TR as an equal partner in the research project and to follow her lead in designing an inquiry into her teaching practice. At the same time, the UR was influenced by her own role as a pre-tenure faculty member facing demands for scholarly productivity. While the UR continually reflected on the division of labor between the TR and UR and articulated some rules of participation (intended to increase the TR's sense of safety and comfort with the process and to position the TR as the driver of the process), the internal tension inherent in membership in different communities certainly shaped the UR's participation in the unfolding PD activity.

\section{Data Collection}

Data were collected at two levels. At the first level, we captured classroom discourse during reading instruction through videotaped observations. One or two morning reading blocks were recorded each week throughout one semester (14 weeks), for a total of 30 hours of video. In addition, the UR conducted semistructured, audio-recorded interviews with seven students ( 3 girls and 4 boys; 3 
European American, 2 Latino, 1 mixed race; 1 African American; 3 reading below grade level, 2 reading on level, and 2 reading above grade level), and wrote field notes and extensive reflective memos. These reflections guided the selection of video excerpts to be explored during weekly PD sessions.

For the second level of the study, the TR and UR viewed, analyzed, and discussed video excerpts during weekly sessions (2.5-3.5 hours per session). A semi-structured interview at the start of the semester addressed the TR's goals for her students as readers and participants in discussions. This interview and all of the PD sessions were audio-recorded and transcribed. Both the TR and the UR wrote weekly reflections addressing the content of the discussions and the PD process, including perceptions of the role each researcher was playing and the goals of the experience.

\section{Data Analysis}

Our approach to analyzing data drawn from the PD experience was separate from, though related to, our analysis of classroom discourse data during the PD experience. The UR's aim in the PD sessions was to help the TR take up conceptual and practical tools for analyzing discourse so that she could conduct basic discourse analysis of talk in her classroom. This process was the object of inquiry in our analysis of the PD sessions and is described in the findings.

Analysis of data drawn from the PD sessions was a collaborative extension of the PD experience. We used a recursive thematic coding process to 
examine the evolution of the PD activity and the TR's appropriation of practical and conceptual tools. Individually, we open coded the written reflections and transcripts of the weekly PD sessions, which included excerpts of video from the classroom, and then, discussed the codes. Next, we color-coded the reflections and transcripts to reflect the following categories: Practical Teaching Tool, Practical Research Tool, Conceptual Teaching Tool, Conceptual Discourse Analysis Tool, Object/Motive/Goals of PD, Division of Labor in PD, Rules/Social Norms of PD, Changes in Object/Division of Labor/Rules, and Changes in Student Discourse Behaviors. Over multiple iterations, we gradually developed a set of codes (Merriam, 2009) to identify key practical and conceptual tools both for analyzing discourse and for facilitating and teaching discourse in the classroom. For example, we coded the following explanation from the TR as Practical Teaching Tool: Assessment: "I have a formative assessment sheet where like if we're doing inferences about character, then I'd put that and then I would just mark plus if they got it.” An example of the Conceptual Discourse Analysis Tool: Positioning code was this quote from the TR: "Just looking at Felipe [pseudonym], you can tell that he thinks of himself as a reader now because he's participating and he's participating with confidence and he's coming to the table; 'I know this because.' He’s positioning himself as a reader, as the text guy.” We also developed codes to categorize the TR's observations of classroom talk, 
perspectives about classroom talk, and the TR's and UR's construals of the motives of the PD experience.

We created a data display (Miles \& Huberman, 1994) to map our codes over time and examine changes in the TR's observations and appropriation of tools over the course of the semester. As we began to develop and record theories about these changes in memos, we analyzed video of the TR's instructional practice at key points along our timeline to understand the extent to which practical and conceptual tools that emerged in her talk during PD also found their way into her teaching. We coded transcripts of the selected videos and added coded excerpts to our data timeline. This complex display enabled us to crosscheck our theories about the TR's evolving perspectives and appropriation of tools.

\section{Findings}

Our analysis procedures, particularly our focus on evolution of the activity over time, enabled us to identify four overlapping phases of activity that occurred during the PD process. The findings are presented in terms of these four phases. Each phase was characterized by the motives toward which activity was directed, the roles played by the TR and UR, the connections between the PD activity setting and the activity setting of the TR's classroom, and the practical and conceptual tools emphasized.

\section{Phase 1: Exploration and Inquiry Development}


One of the UR's primary goals during the first few PD sessions was to establish the setting as a safe space for reflection and risk taking by the TR. As we viewed videos together, the UR intentionally backed away from providing substantive comments or suggestions, instead posing open-ended questions designed to help the TR reflect on her practice. Further, the UR explicitly took judgmental evaluation off the table to foster a safe climate, as evidenced in this exchange:

UR: Okay. So, we are going to watch some video. Everybody's first instinct is to be really critical of themselves.

TR: Okay.

UR: And so what I want for us to try and do is take evaluation off the table.

TR: Okay.

UR: That's evaluation of like, my teaching stinks, my teaching is great, I hate my voice, my hairdo is wrong, all of that stuff because we both need to honor that you are taking a risk, right? I mean, it's not like I'm going to put it on YouTube and [say] look at her hairdo-

TR: Look at this jerk!

UR: But, you know, it does take courage to [be videotaped and analyze your teaching] and we both know that you're doing this to help you learn and improve your teaching and, you know, it's for the benefit of all, so both of us need to respect you and not- 


\section{TR: Okay.}

The structure of the first few PD sessions was fairly open-ended. While the UR did review the field notes and videos from class observations and use them to organize a set of potentially interesting video segments and a general framework for the sessions, decisions about what to watch and how to respond were made by the TR. The TR's willingness to take risks in the PD setting suggests that the UR's efforts to make her feel safe were successful. For example, we used questions proposed by Rymes (2009, pp. 60-61) as a resource to generate some possible directions for inquiry (e.g., "Are there certain events that occur every day that include talk you would like to understand better?” “Are there certain students who affect talk in particularly favorable or troublesome ways?” “Is there a student who seems to have been pigeonholed as a certain identity?”). When we considered these questions in the context of the TR's classroom, one option that surfaced was to compare the TR's discourse patterns, including her questioning, in the below level and on-level reading groups. The TR's initial response was:

TR: That one seems very interesting to me. It seems very scary because I'm afraid what we would find is that I'm not as rigorous with the low group as I am with the next group.

UR: Yeah. Why do you think that might be? 
TR: . . I I would hope that I would ask the same amount of high-level questions [in both groups], but if we were actually to look at it, I wonder, and that could be huge in my practice of starting to figure out even with kiddos who are reading at a much lower level how to get to that deep level. So it's scary, but exciting to me.

Despite its potential "scariness," of seven or eight options discussed during this session, the TR decided to pursue this line of inquiry, suggesting that the PD setting felt safe to her. This inquiry framed the remainder of our work together.

As planned, the UR also provided some foundational information about core conceptual tools for analyzing discourse mentioned above, using Bloome and his colleagues' (2005) text as a resource. We read aloud and discussed at length several segments from the Bloome, et al. text addressing ideas about the agency of all participants in discourse and the ways discourse practices can locate knowledge (and consequently) power with particular individuals. The UR framed the discussion this way:

UR: The reason we're doing this is to get you, to give you some tools to see more in what's happening in those interactions and how the events are being constructed and also sort of within the kids how they're constructing an understanding of themselves and the practice of reading, right? And whatever we can do to deepen that understanding and help you ... sort of interrogate your 
practice and hopefully improve an already terrific practice, ... then we're doing our job.

Although our analysis and reflection were informal up to this point, some preliminary findings about patterns of talk in the TR's classroom began to surface. For example, the TR noticed that the boys in the group reading below grade level tended to base their inferences exclusively on loose connections to their background knowledge rather than also drawing on the evidence in front of them (such as text) to construct inferences. She also noticed that each boy would contribute a response or interpretation without acknowledging or responding directly to prior student comments. This pattern seemed to be making it difficult for the students to construct complex or layered interpretations because each new claim took the conversation in a new direction. The TR became so interested in these dynamics that she decided to abandon the plan to compare discourse patterns across two groups and focus exclusively on exploring approaches to engaging the group of struggling readers through shifts in discourse practices. While this initial phase was certainly productive, yielding both reflective insights about practice by the TR and an action research focus, a tension surfaced between the TR's motives for the PD activity and the role played by the UR. While the UR was making a concerted effort to avoid offering interpretive comments or suggestions to locate authoritative knowledge with the TR and empower her to develop her own interpretations, the TR was motivated to 
improve her practice supported by direct suggestions from the UR. Toward the end of the first session, the TR articulated her motive this way:

TR: And we need to figure out a time when you and I can sit down and I can pick your brain about teaching strategies and stuff.

\section{UR: Okay.}

TR: Because I'd like to get some of your fantastic knowledge into that. The TR made similar comments during the second and third sessions. According to Engeström (2001), tensions or contradictions within activities are not problems to be avoided, but fuel that feeds the development of those activities (p. 137). As the tension between the TR's motives and the role the UR was striving to play emerged, the UR considered what activity conditions would be most likely to support appropriation of tools by the TR. "The extent of appropriation depends on the congruence of a learner's values, prior experiences, and goals with those of more experienced or powerful members of a culture” (Grossman et al., 1999, p. 15). Rather than trying to persuade or pressure the TR to take up the motives and roles the UR had in mind, the UR decided (with some difficulty and uncertainty) to follow the teacher's lead, even though that meant-somewhat paradoxicallytaking more control over the PD process. After the UR began offering more substantive commentary on the videos and providing some instructional ideas, such as approaches to lessons on making inferences, the TR responded to the shift this way: 
TR: I appreciate that it's very much like a conversation when we're talking. I can see myself getting stressed out if I were the one who was solely responsible for coming up with guiding questions and noticings and such because I... [hoped] that you would bring that expertise with you and hoping that between the two of us we could really look at my instruction and look at teaching reading and come up with some really smart strategies that at the end of this I could walk away with knowing that I'm a better teacher because of the conversations that we've had. So, to have this back and forth type of conversation is exactly what I anticipated. The shift in participant roles and the motive of the PD activity set the stage for the next phase of the process.

\section{Phase 2: Direct Instruction in the Context of Teacher-Driven Inquiry}

The shift in the roles and motives of the activity highlighted practical teaching tools at an earlier stage of the PD process than anticipated by the UR. Further, whereas the UR had intended to support the TR in generating her own practical teaching tools relevant to the findings of her inquiry (in the spirit of avoiding didactic PD), in this phase the UR provided direct instruction about a practical teaching tool. The focus of this phase was introduction of some basic practices of accountable talk (Wolf, Crosson, \& Resnick, 2005). According to Resnick (1999),

Accountable talk seriously responds to and further develops what others in the group have said. It puts forth and demands knowledge that is accurate 
and relevant to the issue under discussion, ... . [and] follows established norms of good reasoning.

While this approach to classroom talk has deep theoretical and philosophical roots (Michaels, O’Connor, \& Resnick, 2008), the focus of our discussion about it was practical. Using slides and some online materials (e.g., Denver Public Schools, 2005; Strategic Educational Research Partnership, 2008), we addressed questions like: What can it sound like? How might you introduce it? What might be some useful sentence frames to get students started?

On the day following our review of these materials, the TR presented "accountable talk"i to her class. Prior to the beginning of the study, the TR had set up a structure for class discussion during carpet time in which each speaker was to stand up, move to the edge of the group so that everyone could see him, and wait for all eyes to focus on him before speaking. Once he had finished speaking, he would sit down. The TR layered accountable talk as a practice on top of this management structure and added the expectation that once a student shared her idea, she would remain standing and subsequent speakers would direct their comments to her. At the beginning of her first "accountable talk" lesson, the TR presented a chart that listed “Ways to Enter the Conversation”: I agree because, I disagree because, I also noticed, I'd like to add, What you said made me think about, and I have a question. The TR explained that when students wanted to join the conversation, they would need to begin with one of these 
stems. Then she presented a topic for debate, asking students to imagine that she was the principal and that she was considering banning Silly Bands (stretchy bracelets worn and played with by many students). She asked, "Should Silly Bands be banned? Come up with your reasons why.” After providing some time to think privately, the TR opened the floor to discussion.

After the first student shared her opinion, the TR called on herself and modeled using a sentence stem to enter the conversation. Then she invited other students to join the conversation and coached them to use the sentence stems to direct their comments to one another and to remain standing after their turn. A somewhat awkward and halting but thorough exploration of the topic of a Silly Band Ban developed. The TR followed this discussion with an opportunity for reflection on the process and then opened up a discussion about this approach to classroom talk. The students were not sold on "accountable talk" as it had been presented at this point, expressing reluctance to use the sentence stems, but they were beginning to use the stems nonetheless.

Over the course of the semester, the TR continued to coach students to use the sentence stems in whole and small group reading discussions, placing particular emphasis on the "I agree/disagree with [student name] because__ stem. The effect that this one new practice had on the discourse in the classroom was profound. Our observations in the classroom and analysis of the videos showed us that within a few days, students were taking up 
the talk moves more naturally during whole group instruction. During the Sunday PD session following the Monday "accountable talk" introduction, the TR said:

TR: I feel like the ... dialog that's happening amongst my students in just a week of introducing that information has changed significantly and I can only imagine what it will be like by the end of the year. . . So, I just, I feel that in the very, very basic stages of this kind of discussion in class they're really starting to go deeper and to connect with one another.

The school counselor, who is a highly respected leader in the school, facilitated a lesson on bullying a couple of days after the first lesson on the sentence stems. The students effectively used the stems during the discussion, and later, the counselor said, "I teach in every classroom in this building and I’ve never participated in a conversation that was as well structured and as rich as [that bullying] conversation.”

For the next several weeks, during the TR's unit on constructing inferences, the students began to use the sentence stems to analyze texts more deeply, building and defending arguments to support inferences. In the small group of struggling readers, we noticed pronounced changes both in talk patterns and in students' use of evidence to support claims about texts. Late in the semester, these boys used phrases like, "I disagree with Kelvin because it says right here [pointing to the text] that the poachers wanted to kill Dian Fossey” to defend their interpretations, representing a dramatic shift in their talk about texts. 
While the TR's implementation of a practical teaching tool (i.e., sentence stems derived from “accountable talk”) yielded encouraging results for students, one might argue that by focusing on the surface features of the tool without emphasizing its conceptual underpinnings, the UR may have short-circuited the TR's opportunity to learn and develop adaptive expertise. According to Grossman and her colleagues (1999),

If a tool is presented without its conceptual underpinnings, [teachers] may appropriate only what's available, that is, the label and surface features ... We hypothesize that such approaches limit teachers' likelihood of understanding the conceptual underpinnings of the tool and their chances of applying it to handle new situations or to solve new problems. (p. 19) Based on this concern, the UR was initially hesitant to shift the roles and motive of the PD activity to emphasize a practical teaching tool (rather than conceptual tools for thinking about discourse). However, we discovered in Phase 3 that the TR's use of a practical teaching tool she did not yet fully understand enabled her to deepen her conceptual understandings about talk.

\section{Phase 3: From Practical Tools to Conceptual Tools: The Power of Listening} Whereas many PD opportunities might begin and end with the delivery of a practical teaching tool such as a curriculum or a set of graphic organizers, our shared analysis of and reflection on classroom discourse practices continued well beyond the introduction of some threads of the "accountable talk" approach. We 
used our weekly PD sessions as opportunities to examine students’ appropriation of the sentence stems and the ways in which these stems helped them to construct more robust arguments and inferences about texts. In this context, the TR began to listen differently to the talk unfolding in her class, making observations about both form (e.g., sequences of turn-taking, frequency of participation by more reticent students) and substance (e.g., the logical connections among propositions made by different students, the sources of evidence used to support propositions). Through this process, the TR increasingly took the student perspective, articulating concerns about how a particular teacher utterance might have made a student feel or how the student might have interpreted it. Although she was not yet regularly using terminology like "location of knowledge” or “positioning," this shift in the TR's observations suggests that she was beginning to take up these concepts.

The TR also began to consider the possible thinking processes behind unconventional student interpretations and unexpected student answers. At the start of the process, the TR characterized some unexpected responses as "off base” or "in left field,” and framed discussions of texts in terms of getting students to a pre-determined “correct” interpretation. By the end of the semester, she was beginning to explore the value of discussions in which students articulated interpretations, supported their claims with textual evidence, and debated one another's claims without necessarily arriving at the interpretation in 
the TR's mind. Further, she began to consider ways in which students' unexpected responses might be based on some logic or plausible grounds. For example, in a discussion with the group of struggling readers about Stone Fox (Gardiner, 1980), the TR tried to get students to draw on their schemas to help them figure out why a state official might be paying a visit to Willy and his grandfather. (It turns out that the official is there to demand payment on an overdue tax bill, which sets up the key problem of the novel.) The boys suggested that the visitor was likely there to help Willy, to offer him and his grandfather money, food, or a job. The conversation went on for several minutes, with the TR pushing students to see that the visitor's “official business” was probably negative. As we watched the video of this discussion together, the TR paused it at this point. The UR asked,

UR: What are you thinking?

TR: Maybe they just don't . . . have that schema of foreclosure and people take your-I mean, I wonder how many of these kiddos have families that own homes or how many of them rent. I wonder how many of them hear parents talking about mortgage payments, you know what I mean? Like, I don't know. They may have zero schema on this idea that when you don't pay your bills, taxman comes out and gets you. You know? 
UR: Right. It seems like with that in mind, they make some good attempts . . . because it's also like when you don't have any money social services sometimes comes out to help you.

TR: Exactly. See, I didn't even think about that.

UR: It's hard-I mean, what we're kind of getting to is . . how do we as readers know which parts of our schema are relevant?

Over the last few PD sessions, the TR increasingly critiqued her own discourse moves when she realized that she was insisting on one way of thinking about a text when a student might have been trying to articulate another valid way of thinking. She looked for windows into their thinking and began to give students the "benefit of the doubt" more frequently.

During the data analysis process, as we examined the transcript from our first PD session, the TR noticed the section in which she described her practice of having students stand and wait for everyone to look at them before speaking. During that first PD session, she had explained:

TR: I've really been trying to train my kids not to talk to me and to talk to one another so you'll often hear me say talk to your classmates, tell your classmates .

UR: Why - I think there's sort of an implicit, really an implicit theory, right, that you have when you decide, "I want them to talk to their classmates." Why is that worth doing? 
TR: Because I want them to recognize that they shouldn't be thinking for me. Like, I feel so often kids want to give suggestions or answers because they want the teacher to see them as being right and the teacher to value them as being smart ... I feel that they're doing it more for my sake than for their own or for the sake of their classmates and I'm trying to get them to share their thinking with one another ... And, you know, what do you think - and we'd get another person to stand up and the dialog would happen across the carpet versus me being in the center of it.

Upon rereading this section of the transcript, the TR pointed out, "I said this, but I was doing nothing to support it. My actions [in the classroom] all positioned me as the expert, the person they should be trying to impress to prove they also have some knowledge.” In this response to her own earlier comments, the TR was using conceptual tools for understanding discourse, such as positioning and the location of knowledge. She was appropriating language the UR had been using throughout the PD process and using it to examine and critique her practice.

\section{Phase 4: Ripples in the Waters of Practice}

The TR continues to structure discussion in her classroom around

“accountable talk” sentence stems. In the first week of the next school year with a new group of students, a parent sent an email about her son, who had suffered from low self-esteem in past years “due to bullying and not feeling like anyone 
cared about his ideas and feelings.” In reference to his new class, the parent reported that her son said, "People listen to me and I can join the conversation."

Other teachers and the principal have taken notice of the changes occurring in the TR's classroom. The TR has had requests from several teachers to demonstrate her approach to facilitating discussion in their rooms and has given an invited presentation on classroom discourse at the Oregon Council of Teachers of English conference on language arts and reading. Further, the school-wide site council has explicitly identified the development of effective conversations using “accountable talk" as one of their official school goals for the school year following our study. Clearly, practical teaching tools can make a big difference in schools.

\section{Discussion}

Cazden (1981) differentiated between "performance without competence” and “performance before competence," reminding educators that "assisted performance does indeed contribute to subsequent development” (p. 7). In the case described here, we seem to have performance of the surface features of a practical teaching tool before competence in articulating the conceptual underpinnings of the tool within the context of ongoing support and assistance. Teacher educators often feel a tension between engaging students (including inservice teachers) in rigorous, conceptually-rich experiences and providing practical tools teachers can apply immediately in their classrooms. That tension is 
often exacerbated by the desire of pre-service and in-service teachers to walk away from teacher education experiences with ready-to-use materials and ideas. Early in this study, the TR articulated that perspective, saying: "I want to know what am I going to take from this to apply to my teaching tomorrow.” Such a request can be frustrating to teacher educators who feel a professional responsibility to arm teachers with theories and concepts they can use to navigate a range of situations and to position them as intellectually capable decisionmakers, rather than as implementers of static practices. What makes this study particularly interesting is not the TR's desire for practical teaching tools or the UR's decision to provide some, but what happened next (and continues to happen) as a result. The UR offered a thread of “accountable talk" as a practical teaching tool within the context of a teacher-driven inquiry into the TR's practice. As the TR implemented the practice, we sustained analytical and reflective dialogue around it for several weeks, supporting the TR's appropriation not only of the practical teaching tool, but also of conceptual tools for analyzing and understanding classroom discourse.

It might appear that the PD process would have been more efficient had the UR presented the “accountable talk” stems as a practical teaching tool during the first session. We spent multiple sessions engaged in open-ended reflection on classroom video and gradually formulating an inquiry, which could be interpreted as ineffiecient. In reality, the relevance of this practical teaching tool (the 
“accountable talk" stems) only emerged as a result of the first phase of the PD process. Other practical tools for facilitating classroom talk (e.g., posing authentic vs. display questions) might have been presented to the teacher, but “accountable talk” most directly addressed her concern that students were not building coherent arguments about texts together. Perhaps more importantly, the TR explained that had the UR approached the first couple of PD sessions in the more "didactic" role she played during Phase 2 of the project, the TR might have been "turned off" from the process. She explained during the data analysis that such an approach might have "shut down [her] thinking and positioned [the UR] as the person in charge of thinking."

In a recent address, Engeström (2011) proposed “formative intervention” as a preferred approach to activity theory research, arguing that "all research intervenes ... We cannot stay outside [of the contexts we study]; we can only pretend to do so.” Engeström argued that the inherently interventionist role of all research can put a researcher in a position to intervene "deliberately and methodically” and thereby to create "possibility knowledge.” While we set out to use action research driven exclusively by the TR as our inquiry approach, as our activity developed, the UR intervened deliberately and thoughtfully. We believe that by drawing together-or moving back and forth between-an exclusively teacher-driven inquiry approach and a more interventionist approach, we were able to make the most of the time the TR was able to devote to the professional 
development process. Passing the lead role back and forth between the TR and UR enabled us to locate and explore a problem of particular interest to the TR and also to leverage the work already done by other scholars and practitioners to make substantial, concrete changes in the TR's practice. The TR was able to investigate her practice and formulate her own interpretations, but was not left to reinvent the wheel when a "wheel” that could at least get her moving in the direction of helping her students build more coherent, cohesive conversations was already available. By driving along on that new wheel and investigating how talk changed in her classroom with the support of the UR, the TR developed conceptual understandings about how students learn through talk, how they can be positioned through talk, and how talk moves can signal the location of authoritative knowledge.

It is important to note that the TR's instruction was strong prior to her participation in this project. When our work began, the TR was already providing cognitive modeling of comprehension strategy use in the context of reading authentic texts, offering students frequent and varied opportunities to share their thinking and try out strategies, helping students locate high-interest, accessible texts, engaging students in discussions focused on authentic texts, and providing explicit instruction about social norms for participation. We believe that this context makes the process and outcomes of our work more compelling. Even 
strong teachers can grow their practices through sustained PD that responds to their needs and treats them with respect. ${ }^{\mathrm{ii}}$

Scholars, professional developers, and teachers have been aware for some time that one-shot, didactic PD is generally ineffective. We know that coaching and other long-term, responsive structures are more productive formats for meaningful PD (Webster-Wright, 2009). This case provides an example of the value of a professional developer "sticking around" with a teacher, but it also goes further. It encourages professional developers to actively seek opportunities to set aside their own agendas, to listen thoughtfully, to give teachers what they ask for, not what we think they need. It tells us to have faith in teachers to find their way to conceptual understandings and adaptive expertise with our support, rather than assuming that honoring their requests for usable practical teaching tools will relieve them of the responsibility or motivation to develop conceptual understandings.

An important part of the project of opening up opportunities in our profession is including teachers as active intellectual participants with access to the theoretical and analytical tools that enable researchers to see what they see in classrooms. This paper reports on an attempt to open such opportunities through collaborative, teacher-driven research and highlights the ways in which the different perspectives researchers and teachers bring to interactions shape how they unfold. While we believe that theoretical and conceptual understandings are 
essential to effective teaching, our findings underscore the value of respecting teachers' practical and intellectual agendas in PD contexts. Teacher educators often lament teachers' insistence on practical, rather than theoretical, tools and activities that can be used "tomorrow." This study suggests that if we honor teachers' purposes, offer them practical tools they can use, and sustain ongoing intellectual relationships with them, we can help them link the practical to the conceptual and prepare them to solve the novel problems we know they will face over the course of hundreds of tomorrows.

We imagine a model of professional development in which the role of leader or agenda-setter moves fluidly back and forth between teachers and professional developers. Alternating between periods of open observation, problem finding, and inquiry into local practice driven by teachers and periods during which professional developers share knowledge developed by scholars and practitioners that is targeted to teachers' interests and needs could yield powerful learning. Such a model supports teacher ownership and agency, addresses problems of practice important to teachers, and simultaneously values and takes advantage of the knowledge the professional developer brings to the activity. We believe that such an approach can offer immediate, concrete improvements in practice without sacrificing the development of conceptual tools that will enable teachers to solve novel problems. 


\section{References}

Bloome, D., Carter, S. P., Christian, B. M., Otto, S., \& Shuart-Farris, N. (2005).

Discourse analysis and the study of classroom language and literacy

events: A microethnographic perspective. Mahwah, NJ: Lawrence Erlbaum.

Boushey, G. \& Moser, J. (2006). The daily five: Fostering literacy independence in the elementary grades. Portland, ME: Stenhouse.

Bransford, J., Derry, S., Berliner, D., Hammerness, K., \& Beckett, K. L. (2005). Theories of learning and their roles in teaching. In L. Darling-Hammond \& J. Bransford (Eds.), Preparing teachers for a changing world: What teachers should learn and be able to do (pp. 40-87). San Francisco, CA: Jossey-Bass.

Cazden, C. B. (1981). Performance before competence: Assistance to child discourse in the zone of proximal development. Quarterly Newsletter of the Laboratory of Comparative Human Cognition, 3, 5-8.

Cole, M. (1996). Cultural psychology: A once and future discipline. Cambridge, MA: Harvard University Press.

Denver Public Schools. (2005, December 12). Accountable talk. Retrieved from: http://csss.dpsk12.org/secure/principals/cd_curric_docs_principaltools.htm 
Engeström, Y. (1987). Learning by expanding: An activity-theoretical approach to developmental research. Helsinki, Finland: Orienta-Konsultit.

Engeström, Y. (2001). Expansive learning at work: Toward an activity-theoretical conceptualization. Journal of Education and Work, 14, 133-156.

Engeström, Y. (2011, April). Intervening to shape the future. Presidential session presented at the annual conference of the American Educational Research Association, New Orleans, LA. Retrieved from: http://cmcgc.com//Media/Synch/310442/120/player.html

Gamoran, A., \& Nystrand, M. (1991). Background and instructional effects on achievement in eighth-grade English and social studies. Journal of Research on Adolescence, 1, 233-300.

Gardiner, J. R. (1980). Stone fox. New York, NY: HarperCollins.

Garet, M. S., Porter, A. C., Desimone, L., Birman, B.F., \& Yoon, K. S, (2001). What makes professional development effective? Results from a national sample of teachers. American Educational Research Journal, 38, 915-945.

Grossman, P. L., Smagorinsky, P., \& Valencia, S. (1999). Appropriating tools for teaching English: A theoretical framework for research on learning to teach. American Journal of Education, 108, 1-29.

Harré, R., \& van Langenhove, L. (1998). Positioning theory: Moral contents of intentional action. Oxford, England: Blackwell. 
Hatano, G., \& Inagaki, K. (1986). Two courses of expertise. In H. A. H.

Stevenson \& K. Hakuta (Eds.), Child development and education in Japan (pp. 262-272). New York, NY: Freeman.

Hawley, W. D., \& Valli, L. (1999). The essentials of effective professional development: A new consensus. In L. Darling-Hammond \& G. Sykes (Eds.), Teaching as the learning profession: Handbook of policy and practice (pp. 127-150). San Francisco, CA: Jossey-Bass.

Kuutti, K. (1996). Activity theory as a potential framework for human-computer interaction research. In B. Nardi (Ed.) Context and consciousness: Activity theory and human-computer interaction (pp. 17-44). Cambridge, MA: MIT Press.

McKeown, M. G., Beck, I. L., \& Blake, R. G. K. (2009). Rethinking reading comprehension instruction: A comparison of instruction for strategies and content approaches. Reading Research Quarterly, 44, 218-253.

Merriam, S.B. (2009). Qualitative research: A guide to design and implementation. San Francisco, CA: Jossey-Bass.

Michaels, S., O’Connor, C., \& Resnick, L. (2008). Deliberative discourse idealized and realized: Accountable talk in the classroom and in civic life. Studies in the Philosophy of Education, 27, 283-297

Miles, M.B., \& Huberman, A.M. (1994). Qualitative data analysis: An expanded sourcebook (2nd ed.). Thousand Oaks, CA: Sage. 
National Center for Education Statistics. (2011). The nation's report card:

Reading 2011 (NCES 2012-457). Washington, DC: Institute of Education Sciences, U.S. Department of Education.

No Child Left Behind (NCLB) Act of 2001, Pub. L. No. 107-110, § 115, Stat. 1425 (2002).

Palincsar, A. S., \& Brown, A. L. (1984). Reciprocal teaching of comprehensionfostering and comprehension-monitoring strategies. Cognition and Instruction, 1, 117-175.

Pine, G. J. (2009). Teacher action research. Thousand Oaks, CA: Sage.

Resnick, L. B. (1999, June 16). Making America smarter. Education Week, pp. 38-40.

Rymes, B. (2009). Classroom discourse analysis: A tool for critical reflection. Cresskill, NJ: Hampton Press.

Strategic Education Research Partnership. (2008). Accountable talk: What does it mean? Retrieved from: http://www.wordgeneration.org/atbigpic.html

Vygotsky, L. S. (1986). Thought and language. (trans. A. Kozulin). Cambridge, MA: MIT Press.

Webster-Wright, A. (2009). Reframing professional development through understanding authentic professional learning. Review of Educational Research, 79, 702-739. 
Wells, G. (2011). Integrating CHAT and action research. Mind, Culture, and Activity, 18, 161-180.

Wertsch, J. V. (1998). Mind as action. New York, NY: Oxford University Press.

Wilson, S. M., \& Berne, J. (1999). Teacher learning and the acquisition of professional knowledge: An examination of research of contemporary professional development. Review of Research in Education, 24, 173-209.

Wolf, M. K., Crosson, A. C., \& Resnick, L. B. (2005). Classroom talk for rigorous reading comprehension instruction. Reading Psychology, 26, 2753.

\footnotetext{
${ }^{\mathrm{i}}$ We use quotation marks around "accountable talk" to signal that only a few components of the approach described by Michaels, O’Connor, and Resnick (2008) were enacted in this study.

${ }^{\text {ii }}$ While the focus of this paper is on the TR's appropriation of practical and conceptual tools and her development of adaptive expertise, we want to make clear that the UR learned a great deal from the opportunity to observe the TR's instruction, to talk about reading with her students, and to reflect on her practice alongside her.
} 